\title{
Serum IGF-1 and IGFBP-3 levels as clinical markers for patients with lung cancer
}

\author{
FARUK TAS, ELIF BILGIN, DIDEM TASTEKIN, KAYHAN ERTURK and DERYA DURANYILDIZ \\ Department of Medical Oncology, Institute of Oncology, University of Istanbul, Capa, Istanbul 34390, Turkey
}

Received December 17, 2015; Accepted March 3, 2016

DOI: 10.3892/br.2016.629

\begin{abstract}
Insulin-like growth factor-1 (IGF-1) and its essential binding protein-3 (IGFBP-3) exhibit significant roles in cellular proliferation, differentiation and apoptosis in numerous malignancies, including lung cancer. The aim of the present study was to determine the clinical roles of the serum IGF-1 and IGFBP-3 levels in lung cancer patients. A total of 80 patients with lung cancer were enrolled in the study. Serum IGF-1 and IGFBP-3 concentrations were determined by ELISA methods. The median age of patients was 58.5 years old, with a range of 36-80 years. The majority of the patients had non-small cell lung cancer (NSCLC) (85\%) and metastatic disease (56\%). No significant differences were observed in serum IGF-1 levels between lung cancer patients and healthy subjects $(\mathrm{P}=0.403)$. However, baseline serum IGFBP-3 levels of the lung cancer patients were significantly lower compared to the control group $(\mathrm{P}<0.001)$. The male patients had elevated serum IGF-1 concentrations compared to females $(\mathrm{P}=0.025)$. Furthermore, patients with NSCLC histology and metastatic stage in NSCLC had elevated serum IGF-1 ( $\mathrm{P}=0.022$ and $\mathrm{P}=0.039$, respectively) and IGFBP-3 $(\mathrm{P}=0.005$ and $\mathrm{P}=0.043$, respectively) levels compared with those with SCLC histology and non-metastatic stage in NSCLC. However, none of the other clinical variables, including age of patient, tumor histology and chemotherapy responsiveness, were observed as correlated with serum assays of IGF-1 and IGFBP-3 (P>0.05). There was a significant association found between IGF-1 and IGFBP-3 serum levels in lung cancer patients $(\mathrm{P}<0.001)$. Neither serum IGF-1 nor IGFBP-3 concentrations were associated with outcome $(\mathrm{P}=0.552$ and $\mathrm{P}=0.471$, respectively). In conclusion, serum concentrations of IGFBP-3 may have a diagnostic predictor in patients with lung cancer compared to serum IGF-1 concentrations. However,
\end{abstract}

Correspondence to: Dr Faruk Tas, Department of Medical Oncology, Institute of Oncology, University of Istanbul, 118 Millet Street, Capa, Istanbul 34390, Turkey

E-mail: faruktas2002@yahoo.com

Key words: serum, insulin growth factor-1, insulin growth factor binding protein-3, lung cancer predictive and prognostic values of the two serum assays were not observed.

\section{Introduction}

Lung carcinoma is a tumor characterized by extremely invasion and metastatic behavior, properties that require interaction of the lung cancer cells with the growth factors. Insulin-like growth factors (IGFs) are one of the prominent families of growth factors observed to be closely involved in the adjustment of cell growth and transformation. IGF-1, a multifunctional protein peptide, has a significant role in cellular growth, proliferation, differentiation and transformation in numerous malignancies, including lung cancer (1-9). In vitro studies show that IGF-1 increments lung cell growth and invasive potential, proposing a role for the IGF-1 pathway in the etiology of lung cancer (1-9). Although numerous studies have observed that IGF-1 has an important role in lung cancer, the clinical survival associated with circulating IGF-1 levels is not clear. The effect of serum IGF-1 on disease relapse and survival in lung cancer patients are investigated as unsatisfactory (1-9). Thus, the clinical significance of serum IGF-1 concentrations in lung cancer patients remains to be elucidated.

The IGF binding protein (IGFBP) family consists of six structurally related proteins; all members are expressed in the normal lung tissue (1-9). Their role is to bind and regulate their effects. IGFBP-3 is the prominent binding protein of IGF-1 and it regulates the mitogenic and antiapoptotic actions of the IGFs. In the majority of studies, IGFBP-3 has been observed to correlate with circulating IGF-1 concentrations. Furthermore, in particularly IGFBP-3 has direct IGF-independent effects on apoptosis and cellular growth. The studies show that IGFBP-3 is correlated with the lung cancer prognosis (1-9). IGFBP-3 may use an inhibitory influence on the growth of lung cancer. Serum concentrations of IGFBP-3 are significantly diminished in lung cancer. Additionally, IGFBP-3 overexpression by lung cancer cells with aggressive biological characteristics has been a paradox.

The importance of the serological IGF-1 and IGFBP-3 concentrations in lung cancer patients remains to be elucidated. Due to conflicting results reported in recent epidemiological and clinical studies investigating the IGF axis and lung cancer, the present study was conducted to investigate whether circulating IGF-1 and IGFBP-3 concentrations have 
diagnostic, predictive and prognostic values in lung cancer patients.

\section{Materials and methods}

Patients. A total number of 80 patients with histologically or cytologically confirmed non-small cell lung cancer (NSCLC) and SCLC treated and followed-up in the Institute of Oncology (Istanbul University, Istanbul, Turkey) were enrolled in the study. The patients had bidimensionally measurable disease without a history of chemo/radiotherapy in the last 6 months. The metastatic diseases were staged with various imaging modalities, such as computed tomography (CT), magnetic resonance imaging and positron emission tomography/CT scan. The pathological diagnosis of lung cancer was established according to the revised World Health Organization classification of lung tumors and staged relying on the revised tumor-node-metastasis staging for lung cancer $(10,11)$.

The clinical history, physical examination, series of biochemistry tests and complete blood cell counts were used as the pretreatment evaluation. Those with Eastern Cooperative Oncology Group performance status $\leq 2$ and appropriate blood chemistry tests received a platinum-based chemotherapy with/without radiotherapy depending on the stage of disease. The response to chemotherapy was evaluated radiologically after 2-3 cycles of chemotherapy, according to the revised Response Evaluation Criteria in Solid Tumors criteria (12). The non-responders to chemotherapy and patients with recurrent diseases were treated with second-line chemotherapy, provided when they had a good performance status. Chemotherapy was discontinued when disease progression or unacceptable toxicity occurred.

A total of 30 age- and gender-matched healthy subjects were included in the study. The study was approved by the Ethics Committee of Istanbul University. Written informed consent was obtained from all the patients.

Measurement of serum IGF-1 and IGFBP-3 levels. Serum samples were drawn from patients and healthy controls by venipuncture and clotted at room temperature on first admission prior to the treatment. The sera were collected following centrifugation and frozen immediately at $-20^{\circ} \mathrm{C}$ until analysis

Serum IGF-1 and IGFBP-3 levels were determined by the Immulite 2000 systems (all from Siemens Healthcare Diagnostics Products Ltd., Sudbury, UK). The Immulite 2000 method is an automated solid-phase, enzyme-labeled chemiluminescent immunometric assay method. Sample pretreatment was accomplished in an onboard dilution step.

Statistical analysis. Median values were used to classify variables and the Mann-Whitney U test was used to compare clinical and laboratory parameters. Survival was calculated from the first admission date to the date of mortality from any cause, or to the last contact with the patient or any family member. Kaplan-Meier test was used to estimate the survival and the differences in survival were evaluated by the log-rank statistics. $\mathrm{P} \leq 0.05$ was considered to indicate a statistically significant difference. Statistical analysis was carried out using SPSS 16.0 software (SPSS, Inc., Chicago, IL, USA).
Table I. Patient and disease features.

\begin{tabular}{|c|c|}
\hline Parameter & Patients, $\mathrm{n}$ \\
\hline Total patients & 80 \\
\hline \multicolumn{2}{|l|}{ Age, years } \\
\hline$\geq 60$ & 37 \\
\hline$<60$ & 43 \\
\hline \multicolumn{2}{|l|}{ Gender } \\
\hline Male & 72 \\
\hline Female & 8 \\
\hline \multicolumn{2}{|l|}{ Histology } \\
\hline NSCLC & 68 \\
\hline Adenocarcinoma & 33 \\
\hline Squamous cell & 27 \\
\hline Undifferentiated & 8 \\
\hline SCLC & 12 \\
\hline \multicolumn{2}{|l|}{ Stage } \\
\hline II & 4 \\
\hline III & 30 \\
\hline IV & 34 \\
\hline Limited & 1 \\
\hline Extended & 11 \\
\hline \multicolumn{2}{|c|}{ Response to chemotherapy } \\
\hline Yes & 41 \\
\hline No & 30 \\
\hline
\end{tabular}

NSCLC, non-small cell lung cancer; SCLC, small cell lung cancer.

Table II. Serum values of IGF-1 and IGFBP-3 in lung cancer patients and healthy subjects.

\begin{tabular}{lllr}
\hline & \multicolumn{2}{c}{ Median serum levels (range) } & \\
\cline { 2 - 3 } Serum assay & Patients $(\mathrm{n}=80)$ & Controls $(\mathrm{n}=30)$ & P-value \\
\hline $\mathrm{IGF}-1, \mathrm{ng} / \mathrm{ml}$ & $145.5(15-345)$ & $160.5(58.7-293)$ & 0.403 \\
$\mathrm{IGFBP}-3$, & $3.175(0.62-5.65)$ & $4.235(2.6-5.95)$ & $<0.001$ \\
$\mu \mathrm{g} / \mathrm{ml}$ & & & \\
\hline
\end{tabular}

IGF-1, insulin-like growth factor-1; IGFBP-3, IGF binding protein-3

\section{Results}

Patient characteristics. A total of 80 pathologically confirmed lung cancer patients were enrolled in the study. Baseline histopathological and demographic data of patients are listed in Table I. The median age of patients was 58.5 years old, with a range of 36-80 years, where males constituted the majority of the group $(n=72,90 \%)$. The predominance of the patients had NSCLC $(n=68,85 \%)$ and metastatic disease $(n=45,56 \%)$. 
Table III. Comparisons between the IGF-1/IGFBP-3 assays and clinical parameters.

\begin{tabular}{lcc}
\hline Parameter & $\begin{array}{c}\text { Median IGF-1, } \\
\text { ng/ml (range) }\end{array}$ & $\begin{array}{c}\text { Median IGFBP-3, } \\
\mu \mathrm{g} / \mathrm{ml} \text { (range) }\end{array}$ \\
\hline $\begin{array}{c}\text { Age, P-value } \\
\geq 60 \text { years }\end{array}$ & 0.596 & 0.707 \\
$<60$ years & $147(30.90-330)$ & $3.23(0.74-5.38)$ \\
Gender, P-value & 0.025 & $3.16(0.62-5.65)$ \\
Male & $154(12-345)$ & $3.26(0.32-5.65)$ \\
Female & $111(15-166)$ & $2.76(0.82-4.34)$ \\
Histology, P-value & 0.022 & 0.039 \\
NSCLC & $162(12-345)$ & $3.29(0.74-5.65)$ \\
SCLC & $114(39.7-199)$ & $2.84(0.62-3.71)$ \\
Histology in NSCLC, & 0.667 & 0.427 \\
P-value & & \\
Adeno & $167(12-304)$ & $3.32(1.14-5.54)$ \\
Epidermoid & $146(30.9-330)$ & $3.23(0.74-5.65)$ \\
Stage in NSCLC, & 0.005 & 0.043 \\
P-value & & \\
Non-metastatic (I-III) & $141(12-260)$ & $3.17(0.74-5.58)$ \\
Metastatic (IV) & $212(15-330)$ & $3.72(1.14-5.65)$ \\
Response to & 0.514 & 0.710 \\
chemotherapy, P-value & & \\
$\quad$ Yes & $142(30.9-273)$ & $3.28(0.74-5.58)$ \\
No & $154(41.9-345)$ & $3.17(0.62-5.27)$ \\
\hline
\end{tabular}

IGF-1, insulin-like growth factor-1; IGFBP-3, IGF binding protein-3; NSCLC, non-small cell lung cancer; SCLC, small cell lung cancer.

Serum concentrations. No significant difference was determined in the serum IGF-1 concentration between lung cancer patients and healthy individuals (median values, 145.5 vs. 160.5 ng/ml; P=0.403) (Table II and Fig. 1A). However, baseline serum IGFBP-3 concentrations of the lung cancer patients were significantly lower compared to the control group (median values, 3.175 vs. $4.235 \mu \mathrm{g} / \mathrm{ml}$; $\mathrm{P}<0.001$ ) (Table II and Fig. 1B).

Table III demonstrates the correlations between the serum levels of IGF-1 and IGFBP-3 and known clinicopathological factors. The male patients had elevated serum IGF-1 concentrations compared to female patients $(\mathrm{P}=0.025)$. Furthermore, patients with NSCLC histology and metastatic stage in NSCLC had elevated serum IGF-1 $(\mathrm{P}=0.022$ and $\mathrm{P}=0.005$, respectively) and IGFBP-3 ( $\mathrm{P}=0.039$ and $\mathrm{P}=0.043$, respectively) levels compared with those with SCLC histology and non-metastatic stage in NSCLC. However, no other clinical features, including age of patient, tumor histology and chemotherapy responsiveness, were correlated with serum assays of IGF-1 and IGFBP-3 ( $>>0.05)$.

There was a significant association between the serum concentrations of IGF-1 and IGFBP-3 in patients with lung cancer ( $\mathrm{rs}=0.804, \mathrm{n}=80, \mathrm{P}<0.001$, Spearman's correlation) (Fig. 2).

Follow-up. The median follow-up time was 58 weeks, with a range of 3.7-149.3 weeks. The median survival was 94.4 weeks

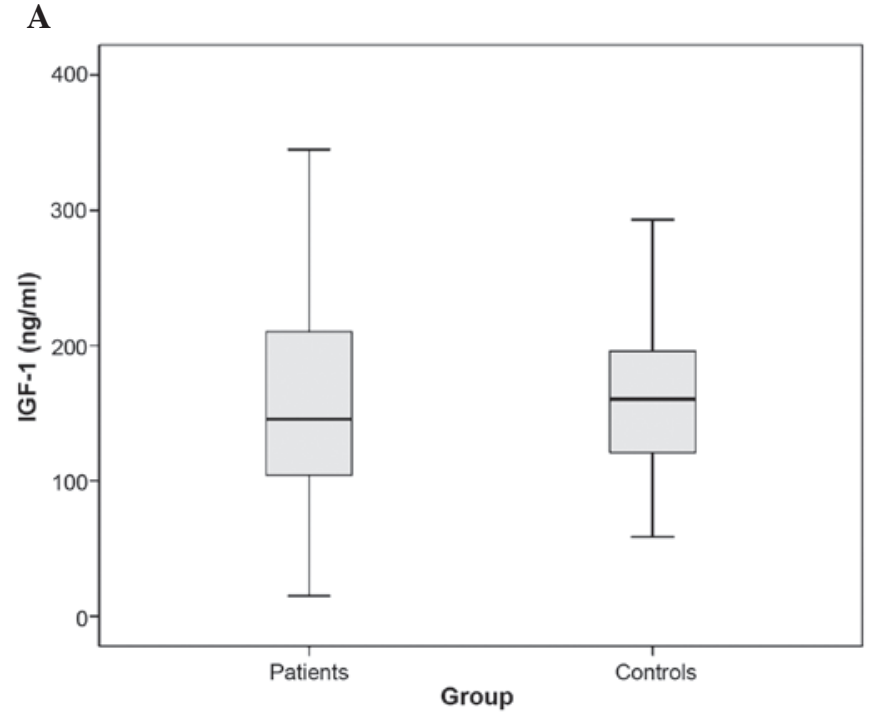

B

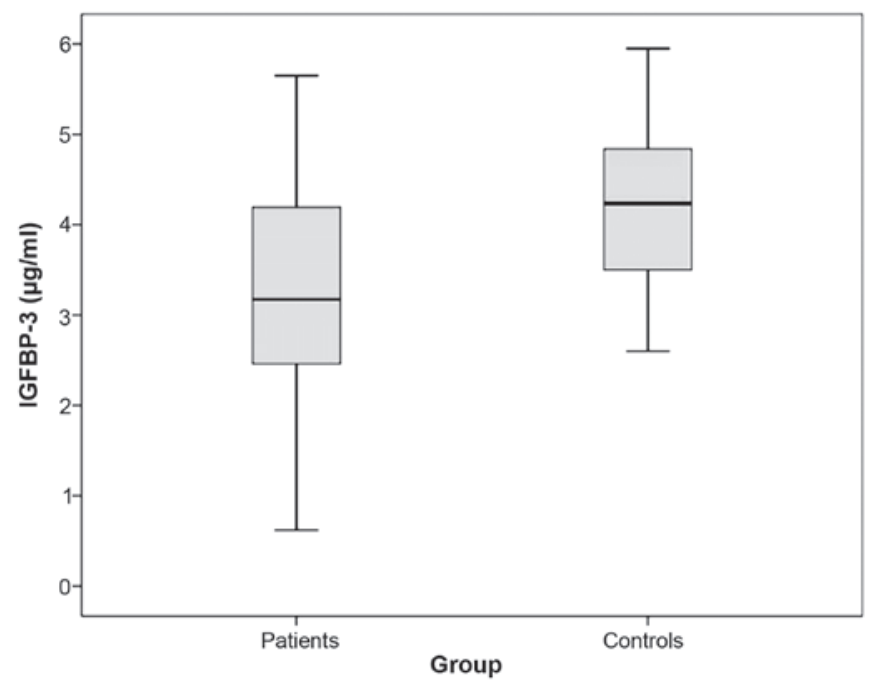

Figure 1. Value of the serum (A) IGF-1 assay and (B) IGFBP-3 assay in lung cancer patients and healthy controls $(\mathrm{P}=0.403$ and $\mathrm{P}<0.001$, respectively). IGF-1, insulin-like growth factor-1; IGFBP-3, IGF binding protein-3.

(95\% confidence interval, 73.1-115.7). The 1- and 2-year overall survival rates were 68.5 and $40.6 \%$, respectively. As expected, histology $(\mathrm{P}=0.004)$, metastasis $(\mathrm{P}=0.005)$ and response to chemotherapy $(\mathrm{P}=0.009)$ had prognostic factors on survival (Table IV). However, serum IGF-1 and IGFBP-3 concentrations were not associated with outcome $(\mathrm{P}=0.552$ and $\mathrm{P}=0.471$, respectively) (Table IV and Fig. $3 \mathrm{~A}$ and $\mathrm{B}$ ).

\section{Discussion}

There is a hypothesis that circulating concentrations of IGF-1 and IGFBP-3 may be significant in determining lung cancer risk. In a case-control study consisting of 208 lung cancer patients, an elevated plasma level of IGF-1 and decreased plasma IGFBP-3 concentration was associated with an increased risk of lung cancer (1). However, in other case-control studies, no correlation was found between serum IGF-1 concentration and lung cancer risk; only high serum concentrations of IGFBP-3 were associated with a reduced lung cancer risk (2-4). 
Table IV. Univariate survival analyses.

\begin{tabular}{|c|c|c|c|}
\hline Parameter & $\begin{array}{c}\text { Median } \\
\text { survival time } \\
\text { week } \pm \mathrm{SE}\end{array}$ & $\begin{array}{c}1 \text {-year } \\
\text { survival } \\
\text { rate } \pm \mathrm{SD}, \%\end{array}$ & P-value \\
\hline $\begin{array}{l}\text { Age of patients, } \\
\text { years }\end{array}$ & & & 0.43 \\
\hline$\geq 60$ & $69.6 \pm 21.8$ & $61.0 \pm 8.6$ & \\
\hline$<60$ & $100.9 \pm 14.9$ & $71.8 \pm 7.3$ & \\
\hline Gender & & & 0.75 \\
\hline Male & $100.9 \pm 10.3$ & $68.6 \pm 5.7$ & \\
\hline Female & $69.1 \pm 35.7$ & $64.3 \pm 21.0$ & \\
\hline Histology & & & 0.004 \\
\hline NSCLC & $100.9 \pm 9.6$ & $72.4 \pm 5.7$ & \\
\hline SCLC & $51.4 \pm 27.1$ & $45.8 \pm 15.0$ & \\
\hline $\begin{array}{l}\text { Histology in } \\
\text { NSCLC }\end{array}$ & & & 0.811 \\
\hline Adeno & $100.9 \pm 13.1$ & $75.7 \pm 8.1$ & \\
\hline Epidermoid & $101.3 \pm 13.9$ & $71.1 \pm 9.4$ & \\
\hline Stage in NSCLC & & & 0.005 \\
\hline $\begin{array}{l}\text { Non-metastatic } \\
\text { (II-III) }\end{array}$ & $149.3 \pm 0.0$ & $81.9 \pm 6.7$ & \\
\hline Metastatic (IV) & $67.0 \pm 18.3$ & $56.3 \pm 9.7$ & \\
\hline $\begin{array}{l}\text { Response to } \\
\text { chemotherapy }\end{array}$ & & & 0.009 \\
\hline Yes & $149.3 \pm 0.0$ & $77.8 \pm 6.5$ & \\
\hline No & $69.6 \pm 18.9$ & $56.7 \pm 10.1$ & \\
\hline $\begin{array}{l}\text { Median serum } \\
\text { IGF-1 level }\end{array}$ & & & 0.552 \\
\hline Normal & $94.4 \pm 22.1$ & $64.9 \pm 7.9$ & \\
\hline Elevated & $84.4 \pm 0.0$ & $68.6 \pm 8.0$ & \\
\hline $\begin{array}{l}\text { Median serum } \\
\text { IGFBP-3 level }\end{array}$ & & & 0.471 \\
\hline Normal & $94.4 \pm 23.0$ & $66.4 \pm 7.6$ & \\
\hline Elevated & $100.9 \pm 13.6$ & $70.6 \pm 7.9$ & \\
\hline
\end{tabular}

SE, standard error; SD, standard deviation; IGF-1, insulin-like growth factor-1; IGFBP-3, IGF binding protein-3; NSCLC, non-small cell lung cancer; SCLC, small cell lung cancer.

In literature, only a limited number of trials have studied serum IGF-1 and IGFBP-3 levels in human lung cancer (5-9). Firstly, Lee et al (5) measured the serum levels of IGF-1 and IGFBP-3 in 41 lung cancer patients (5). The serum IGF-1 levels in the lung cancer patients was significantly lower compared to the controls $(\mathrm{P}<0.01)$ and NSCLC patients showed significantly reduced serum concentrations of IGF-1 compared with SCLC patients $(\mathrm{P}<0.01)$. Similarly, they found that squamous cell carcinoma patients tended to exhibit reduced IGF-1 serum concentrations compared to those with adenocarcinoma histology. Similar to IGF-1, the concentration of IGFBP-3 was significantly lower in lung cancer patients compared with healthy subjects $(\mathrm{P}<0.05)$. However, no significant difference was identified between NSCLC and SCLC groups. These results

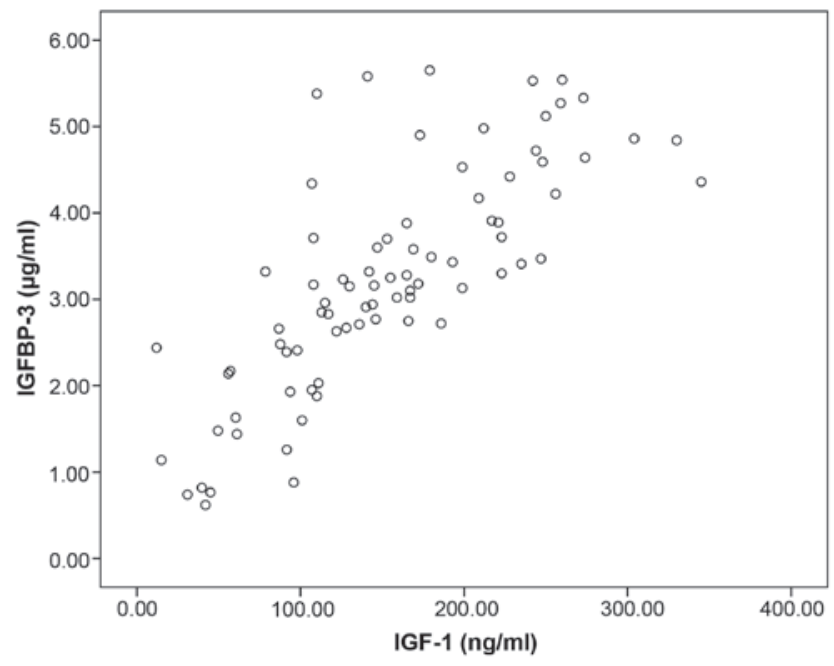

Figure 2. Correlation between serum IGF-1 and IGFBP-3 concentrations in lung cancer patients ( $\mathrm{rs}=0.804, \mathrm{n}=80, \mathrm{P}<0.001$, Spearman's correlation). IGF-1, insulin-like growth factor-1; IGFBP-3, IGF binding protein-3.

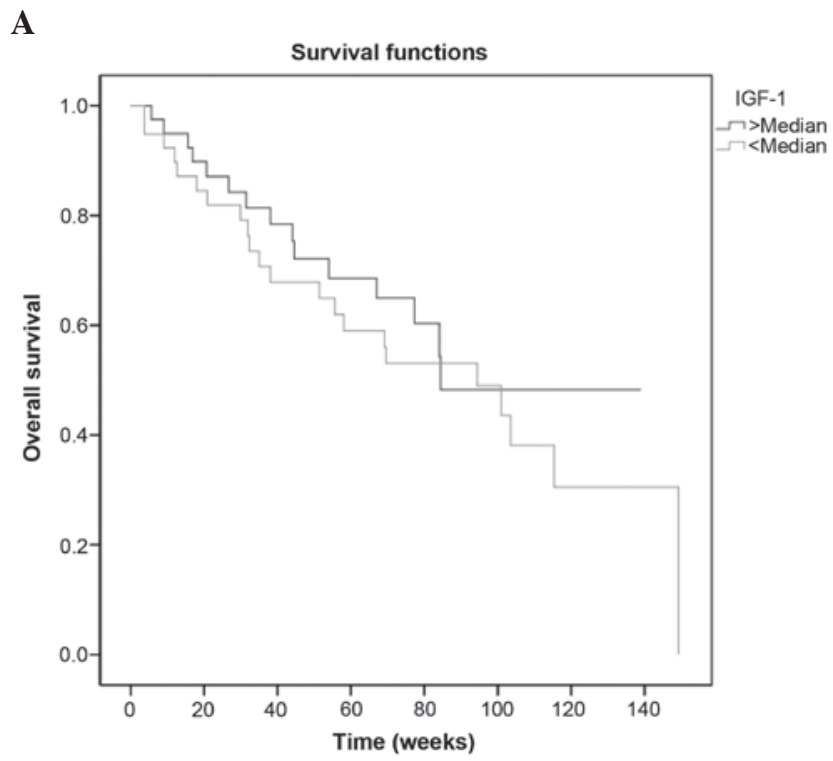

B

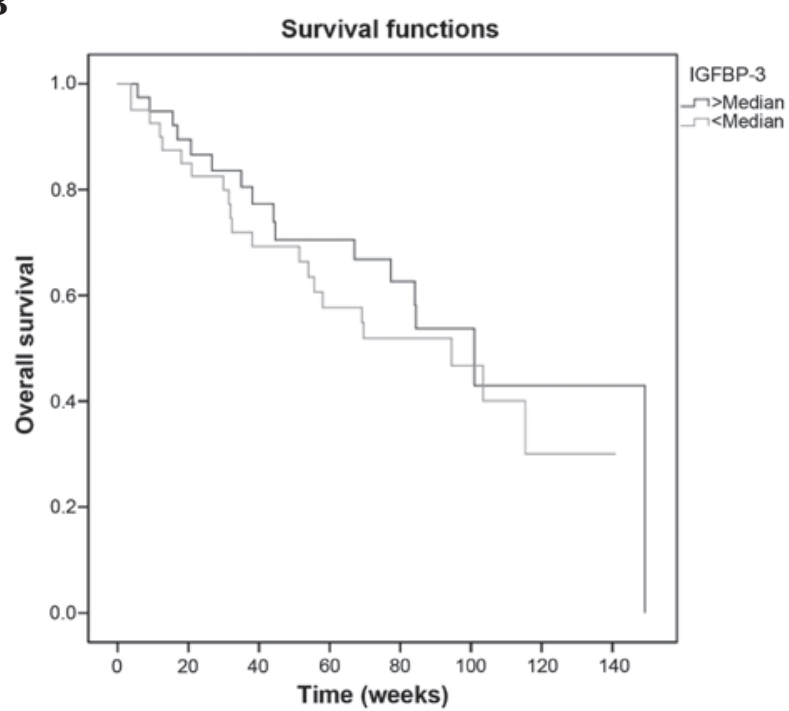

Figure 3. Survival curves in lung cancer patients according to serum (A) IGF-1 concentrations $(\mathrm{P}=0.552)$ and $(\mathrm{B})$ IGFBP-3 concentrations $(\mathrm{P}=0.471)$. IGF-1, insulin-like growth factor-1; IGFBP-3, IGF binding protein-3. 
indicated that serum concentrations of IGF-1 and IGFBP-3 may be useful tumor markers for diagnosing and identifying tumor types of lung cancer. In another study, Unsal et al (6) found that serum IGF-1 and IGFBP-3 concentrations were reduced in 24 lung carcinoma patients compared with normal subjects, but no significant difference was identified between the groups $(\mathrm{P}=0.07$ and $\mathrm{P}=0.06$, respectively). However, the serum IGF-1/IGFBP-3 ratio was significantly reduced in the distant and nodal metastatic patients, and stage of tumor was inversely correlated with this ratio $(\mathrm{P}=0.04)$. Additionally, in a novel study, the expression and clinical significance of IGF-1 and IGFBP-3 were investigated in the serum and cancer tissues from 57 patients with NSCLC (7). Expression levels of IGF-1 in lung cancer tissues and serum from lung cancer patients were significantly increased compared to the control group $(\mathrm{P}<0.05$ and $\mathrm{P}=0.034$, respectively). Conversely, expression levels of IGFBP-3 in cancer tissues and serum in patients were significantly lower compared to the healthy subjects $(\mathrm{P}<0.05$ and $\mathrm{P}=0.042$, respectively). No significant differences were observed for serum IGF-1 and IGFBP-3 levels and the location of tumor, tumor size or pathological grade, but they were significantly associated with lymph node involvement levels, local invasion, distant metastasis and disease stage. The serum levels of IGF-1 and IGFBP-3 in NSCLC patients had a significant inverse correlation $(\mathrm{P}=0.023)$. However, no significant correlation was observed between the expression intensity of IGF-1 and IGFBP-3 ( $\mathrm{P}=0.062)$. Serum IGF-1 levels were significantly different with a positive association at different levels of IGF-1 expression intensity. However, serum IGFBP-3 levels showed no significant differences with a small positive correlation. These findings suggest that IGF-1 upregulation and downregulation of IGFBP-3 may be potential diagnostic biomarkers for NSLCL patients.

Although several studies have assessed the association of circulation concentrations of IGF system with lung carcinoma risk over the last years, little is known regarding the prognostic role of the IGF system in patients with lung cancer. Han et al (8) investigated whether pretreatment IGF-1 and IGFBP-3 levels would predict the prognosis in patients with 77 advanced NSCLC enrolled in a phase II trial of cisplatin plus irinotecan chemotherapy. Serum levels of IGFBP-3 were significantly elevated in female patients $(\mathrm{P}=0.017)$, non-squamous cell cancer $(\mathrm{P}=0.013)$ and no smokers $(\mathrm{P}=0.003)$. However, no statistically significant differences were observed for serum IGF-1 concentrations according to gender, performance status, tumor stage, pathology and smoking behavior. In a univariate analysis, elevated concentrations of IGF-1 and IGFBP-3 were predictive markers of favorable progression-free $(\mathrm{P}=0.001$ and $\mathrm{P}=0.007$, respectively) and overall survival $(\mathrm{P}=0.025$ and $\mathrm{P}=0.001$, respectively). Furthermore, multivariate analysis also revealed that serum IGF-1 and IGFBP-3 were independent prognostic factors for progression-free $(\mathrm{P}<0.0001$ and $\mathrm{P}=0.001$, respectively) and overall survival $(\mathrm{P}=0.004$ and $\mathrm{P}=0.043$, respectively). Increased plasma IGF-1 and IGFBP-3 levels were concluded to be associated with a favorable prognosis in advanced NSCLC patients. In another study, 68 advanced non-squamous NSCLC patients treated with gefitinib were investigated for the prediction to chemotherapy responsiveness and prognostic impacts (9). IGF-1-positive serum predicts a negative response to gefitinib therapy $(\mathrm{P}=0.0003)$. Similarly,
IGF-1 positive was also independent of a poor prognostic factor $(\mathrm{P}=0.04)$. Contrary to IGF-1, the serum level of IGFBP-3 did not have a prognostic factor nor serve as a surrogate predictive marker for the effect of therapy.

In the present study, the serum concentrations of IGF-1 and IGFBP-3 were investigated in 80 patients with different histology and tumor stages of lung cancer who were enrolled in the study. No significant differences were identified in serum IGF-1 concentrations between lung cancer patients and healthy controls ( $\mathrm{P}=0.403)$. However, baseline serum IGFBP-3 levels of the lung cancer patients were significantly lower compared to the control group $(\mathrm{P}<0.001)$. The male patients had elevated serum IGF-1 concentrations compared to females $(\mathrm{P}=0.025)$. Furthermore, patients with NSCLC histology and metastatic stage in NSCLC had elevated serum IGF-1 $(\mathrm{P}=0.022$ and $\mathrm{P}=0.005$, respectively) and IGFBP-3 $(\mathrm{P}=0.039$ and $\mathrm{P}=0.043$, respectively) levels compared with those with SCLC histology and non-metastatic stage in NSCLC. However, no other clinical parameters, such as age of patient, tumor histology and chemotherapy responsiveness, were correlated with serum assays of IGF-1 and IGFBP-3 (P>0.05). There was a significant association between IGF-1 and IGFBP-3 serum levels in patients with lung cancer $(\mathrm{P}<0.001)$. Neither serum IGF-1 nor IGFBP-3 concentrations were associated with outcome $(\mathrm{P}=0.552$ and $\mathrm{P}=0.471$, respectively).

In conclusion, although little is known, findings suggest that the IGF family may have a significant role in the etiology and progression of lung carcinoma in the last years. However, there are numerous controversial findings regarding the patterns of expression of these gene products in the literature; thus, the definitive functional compatibility of these alterations remains to be elucidated. Parallel arguments were true for patterns of quantifying of the circulating serum IGF levels. In the present study, serum concentrations of IGFBP-3 may be a diagnostic marker in lung cancer patients compared to serum IGF-1 concentrations. However, predictive and prognostic values of the two serum assays were not identified. Although the small sample size and the short follow-up time are limitations and may have influenced the results, this study still contributes a significant deal to the literature in that it was carried out with the serum instead of tissue, and it contained all the stages of the disease. Larger-scale studies in larger patient populations are required to determine the exact role of serum IGF-1 and IGFBP-3 levels in lung cancer.

\section{References}

1. Yu H, Spitz MR, Mistry J, Gu J, Hong WK and Wu X: Plasma levels of insulin-like growth factor-I and lung cancer risk: A case-control analysis. J Natl Cancer Inst 91: 151-156, 1999.

2. London SJ, Yuan JM, Travlos GS, Gao YT, Wilson RE, Ross RK and Yu MC: Insulin-like growth factor I, IGF-binding protein 3, and lung cancer risk in a prospective study of men in China. J Natl Cancer Inst 94: 749-754, 2002.

3. Chen B, Liu S, Xu W, Wang X, Zhao W and Wu J: IGF-I and IGFBP-3 and the risk of lung cancer: A meta-analysis based on nested case-control studies. J Exp Clin Cancer Res 28: 89, 2009.

4. Cao H, Wang G, Meng L, Shen H, Feng Z, Liu Q and Du J: Association between circulating levels of IGF-1 and IGFBP-3 and lung cancer risk: A meta-analysis. PLoS One 7: e49884, 2012.

5. Lee DY, Kim SJ and Lee YC: Serum insulin-like growth factor (IGF)-I and IGF-binding proteins in lung cancer patients. J Korean Med Sci 14: 401-404, 1999. 
6. Unsal E, Köksal D, Yurdakul AS, Atikcan S and Cinaz P Analysis of insulin like growth factor 1 and insulin like growth factor binding protein 3 levels in bronchoalveolar lavage fluid and serum of patients with lung cancer. Respir Med 99: 559-565, 2005.

7. Wang Z, Wang Z, Liang Z, Liu J, Shi W, Bai P, Lin X, Magaye R and Zhao J: Expression and clinical significance of IGF-1, IGFBP-3, and IGFBP-7 in serum and lung cancer tissues from patients with non-small cell lung cancer. Onco Targets Ther 6: 1437-1444, 2013.

8. Han JY, Choi BG, Choi JY, Lee SY and Ju SY: The prognostic significance of pretreatment plasma levels of insulin-like growth factor (IGF)-1, IGF-2, and IGF binding protein-3 in patients with advanced non-small cell lung cancer. Lung Cancer 54: 227-234, 2006.
9. Masago K, Fujita S, Togashi Y, Kim YH, Hatachi Y, Fukuhara A, Nagai H, Irisa K, Sakamori Y, Mio T, et al: Clinical significance of epidermal growth factor receptor mutations and insulin-like growth factor 1 and its binding protein 3 in advanced non-squamous non-small cell lung cancer. Oncol Rep 26: 795-803, 2011.

10. Brambilla E, Travis WD, Colby TV, Corrin B, and Shimosato Y: The new World Health Organization classification of lung tumours. Eur Respir J 18: 1059-1068, 2001.

11. Detterbeck FC, Boffa DJ and Tanoue LT: The new lung cancer staging system. Chest 136: 260-271, 2009.

12. Eisenhauer EA, Therasse P, Bogaerts J, Schwartz LH, Sargent D, Ford R, Dancey J, Arbuck S, Gwyther S, Mooney M, Rubinstein L, Shankar L, Dodd L, Kaplan R, Lacombe D and Verweij J: New response evaluation criteria in solid tumours: Revised RECIST guideline (version 1.1). Eur J Cancer 45: 228-247, 2009. 